\title{
Landscape epidemiology of Batrachochytrium salamandrivorans: reconciling data limitations and conservation urgency
}

\author{
Wouter Beukema id $1,2,9$ Jesse Erens (iD,${ }^{1}$ Vanessa Schulz, ${ }^{3,4}$ Gwij Stegen, ${ }^{1}$ Annemarieke Spitzen-van der \\ Sluijs, ${ }^{5}$ Tariq Stark, ${ }^{5}$ Arnaud Laudelout, ${ }^{6}$ Thierry Kinet, ${ }^{6}$ Tom Kirschey, ${ }^{7}$ Marie Poulain, ${ }^{8}$ Claude Miaud, ${ }^{8}$ \\ Sebastian Steinfartz, ${ }^{3}$ An Martel, ${ }^{1}$ and Frank Pasmans ${ }^{1}$ \\ ${ }^{1}$ Wildlife Health Ghent, Faculty of Veterinary Medicine, Ghent University, Salisburylaan 133, Merelbeke 9820 Belgium \\ ${ }^{2}$ Naturalis Biodiversity Center, P.O. Box 9517, Leiden 2300RA the Netherlands \\ ${ }^{3}$ Molecular Evolution and Systematics of Animals, Institute of Biology, University of Leipzig, Talstrasse 33, Leipzig 04103 \\ Germany \\ ${ }^{4}$ Technische Universität Braunschweig, Division of Evolutionary Biology, Zoological Institute, Mendelssohnstrasse 4, \\ Braunschweig 38106 Germany \\ ${ }^{5}$ Reptile, Amphibian \& Fish Conservation Netherlands (RAVON), Toernooiveld 1, Nijmegen 6525ED the Netherlands \\ ${ }^{6}$ Natagora, Traverse des Muses 1, Namur 5000 Belgium \\ ${ }^{7}$ Nature and Biodiversity Conservation Union (NABU), Charitéstrasse 3, Berlin 10117 Germany \\ ${ }^{8}$ Biogeography and Vertebrate Ecology, CEFE, EPHE-PSL, CNRS, University of Montpellier, Paul Valéry University Montpellier III, \\ 1919 route de Mende, Montpellier 34293 France
}

Citation: Beukema, W., J. Erens, V. Schulz, G. Stegen, A. Spitzen-van der Sluijs, T. Stark, A. Laudelout, T. Kinet, T. Kirschey, M. Poulain, C. Miaud, S. Steinfartz, A. Martel, and F. Pasmans. 2021. Landscape epidemiology of Batrachochytrium salamandrivorans: reconciling data limitations and conservation urgency. Ecological Applications 00(00):e02342. 10.1002/eap.2342

Abstract. Starting in 2010, rapid-fire salamander (Salamandra salamandra) population declines in northwestern Europe heralded the emergence of Batrachochytrium salamandrivorans (Bsal), a salamander-pathogenic chytrid fungus. Bsal poses an imminent threat to global salamander diversity owing to its wide host range, high pathogenicity, and long-term persistence in ecosystems. While there is a pressing need to develop further research and conservation actions, data limitations inherent to recent pathogen emergence obscure necessary insights into Bsal disease ecology. Here, we use a hierarchical modeling framework to describe Bsal landscape epidemiology of outbreak sites in light of these methodological challenges. Using model selection and machine learning, we find that Bsal presence is associated with humid and relatively cool, stable climates. Outbreaks are generally located in areas characterized by low landscape heterogeneity and low steepness of slope. We further find an association between Bsal presence and high trail density, suggesting that human-mediated spread may increase risk for spillover between populations. We then use distribution modeling to show that favorable conditions occur in lowlands influenced by the North Sea, where increased survey effort is needed to determine how Bsal impacts local newt populations, but also in hill- and mountain ranges in northeastern France and the lower half of Germany. Finally, connectivity analyses suggest that these hill- and mountain ranges may act as stepping stones for further spread southward. Our results provide initial insight into regional environmental conditions underlying Bsal epizootics, present updated invasibility predictions for northwestern Europe, and lead us to discuss a wide variety of potential survey and research actions needed to advance future conservation and mitigation efforts.

Key words: amphibian; Bsal; Chytridiomycosis; Circuitscape; connectivity; conservation prioritization; distribution model; emerging infectious disease; landscape ecology; population declines.

\section{INTRODUCTION}

Amphibian diversity worldwide is under threat by environmental change. Among the main stressors that fuel this crisis are habitat loss, invasive species, chemical pollution, and disease, which either act alone or in synergy as drivers of decline and local extinction (Stuart

Manuscript received 4 June 2020; revised 1 December 2020; accepted 14 January 2021. Corresponding Editor: Trenton W. J. Garner.

${ }^{9}$ E-mail: wouter.beukema@ugent.be et al. 2004, Wake and Vredenburg 2008, Blaustein et al. 2011). The role of disease in this crisis is significant, not in the least because globalization facilitates pathogens to emerge beyond their native ranges (Martel et al. 2014, O'Hanlon et al. 2018). Emblematic for such spread is the panzootic chytridiomycosis. This fungal disease, caused by Batrachochytrium dendrobatidis $(B d)$ and $B$. salamandrivorans (Bsal), has contributed to declines among hundreds of amphibian species following repeated human-mediated spillover from East Asian source populations (O'Hanlon et al. 2018, Byrne et al. 2019, Scheele et al. 2019). 
Thus far, chytridiomycosis-driven amphibian declines are largely attributable to $B d$, as $B s a l$ was only discovered recently following the acute collapse of salamander populations in the Netherlands (Martel et al. 2013, Spitzen-van der Sluijs et al. 2013). Additional Bsaldriven declines were soon reported from adjacent Belgium, and more recently from western and southwestern Germany (Spitzen-van der Sluijs et al. 2016, Lötters et al. 2020). Beyond northwestern Europe, Bsal was introduced together with invasive host species in Catalonia, Spain, where it affects local newt populations (Martel et al. 2020). Mitigating Bsal effects on amphibian populations remains challenging as this pathogen produces encysted fungal spores that facilitate environmental (i.e., free-living) persistence, and benefits from tolerant reservoir hosts (Stegen et al. 2017, Thomas et al. 2019, Bozzuto et al. 2020). As a result, Bsal currently contributes to declines in an increasing number of hosts, and at an increasing number of sites, within its invasive European range (Spitzen-van der Sluijs et al. 2016, Dalbeck et al. 2018, Wagner et al. 2019b, Lötters et al. 2020, Martel et al. 2020). Infection may instigate rapid local mass mortality events as presently witnessed in fire salamander (Salamandra salamandra) populations (Stegen et al. 2017, Schulz et al. 2018, 2020, Wagner et al. 2019b, Lötters et al. 2020). Strong concern exists about the potentially far-reaching impact of Bsal on global salamander and newt diversity, owing to its high pathogenicity to numerous European and American species (Martel et al. 2014, Carter et al. 2020).

There is a pressing need to improve our understanding of Bsal disease ecology to develop mitigation strategies, direct further research, and prioritize conservation (Thomas et al. 2019, Lötters et al. 2020, Martel et al. 2020, Beukema et al. 2021). Species distribution models are a valuable tool to achieve this aim, given their ability to assess pathogen occurrence relative to different environmental factors, and subsequently identify areas susceptible to colonization or spread (Jiménez-Valverde et al. 2011). Various Bsal spatial early-risk assessments have indeed made use of this technique (Yap et al. 2015, Feldmeier et al. 2016, Beukema et al. 2018, EFSA Panel on Animal Health and Welfare et al. 2018, Katz and Zellmer 2018). Yet, uncertainty remains around the environmental conditions conducive to Bsal epizootics, and regional landscape suitability (hereafter "invasibility") to this pathogen, due to various outstanding issues. First, while diagnostic standards exist to determine whether a host is infected with Bsal (Thomas et al. 2018), host sampling is generally performed opportunistically by different stakeholders across different habitats as surveillance priorities following Bsal discovery focused on mapping its invasive range (e.g., Spitzen-van der Sluijs et al. 2016, Lötters et al. 2020). Bsal presence or absence at a site is therefore subject to observer effects, and confounded with occurrence and detection of a range of host species, which affects disentangling relationships between pathogen presence and the environment (Lahoz-Monfort et al.
2014; see also Discussion). Second, as the observed distribution of Bsal in Europe is growing but remains locally clustered, use of distribution models is subject to methodological challenges inherent to recent pathogen emergence (or species invasion) such as spatial autocorrelation and environmental non-equilibrium (e.g., Elith et al. 2010, Václavík and Meentemeyer 2012). Failure to account for these processes may affect model predictions and thereby misdirect conservation efforts (GuilleraArroita et al. 2015, Feldmeier et al. 2019).

Here, we build on a decade of opportunistically collected presence-absence data to describe $B$ sal landscape epidemiology of outbreak sites. We do so in light of the methodological issues that we have described, using a hierarchical modeling framework (Fig. 1) consisting of evaluating parameter importance, distribution modeling, and connectivity modeling. Our results provide initial insight into regional environmental conditions underlying Bsal epizootics, present updated invasibility predictions for northwestern Europe, and lead us to discuss a wide variety of potential survey and research actions needed to advance future conservation and mitigation efforts.

\section{Methods}

\section{Study area and Bsal presence-absence data}

The northwest European Bsal outbreak area is centered on the border between the Netherlands, Belgium, France, Luxembourg, and Germany (Fig. 1a). This region is characterized by a temperate oceanic climate, while continental and Mediterranean conditions predominate toward the east and south. As distribution model predictive uncertainty increases under climates in which Bsal has not been recorded (Beukema et al. 2018) we restricted our study area to $53.95-47.81 \mathrm{~N}$ to 1.48 $9.95 \mathrm{E}$.

We assembled a Bsal presence-absence data set by first amalgamating 279 records obtained through salamander and newt surveys conducted between January 2010 and May 2020 (Fig. 1a, Appendix S1: Table S1). Of these, 149 records originate from published work (Spitzen-van der Sluijs et al. 2013, 2016, Dalbeck et al. 2018, Lötters et al. 2018, Schulz et al. 2018, Wagner et al. 2019a, b, Canessa et al. 2020), while the remaining 130 were collected during recent surveys. Recent survey sites were randomly chosen based on known presence of host species, and in Wallonia stratified per province. During each survey, newts and salamanders were opportunistically located during the day by lifting cover objects on land such as rocks or logs, by dip netting water bodies, or by active searching on land with flash lights at night near aquatic breeding habitats. Most sites were visited once for an unrecorded period of time, by different observers. Using cotton swabs, encountered amphibians were sampled for subsequent real-time PCR analyses (Blooi et al. 2013). 


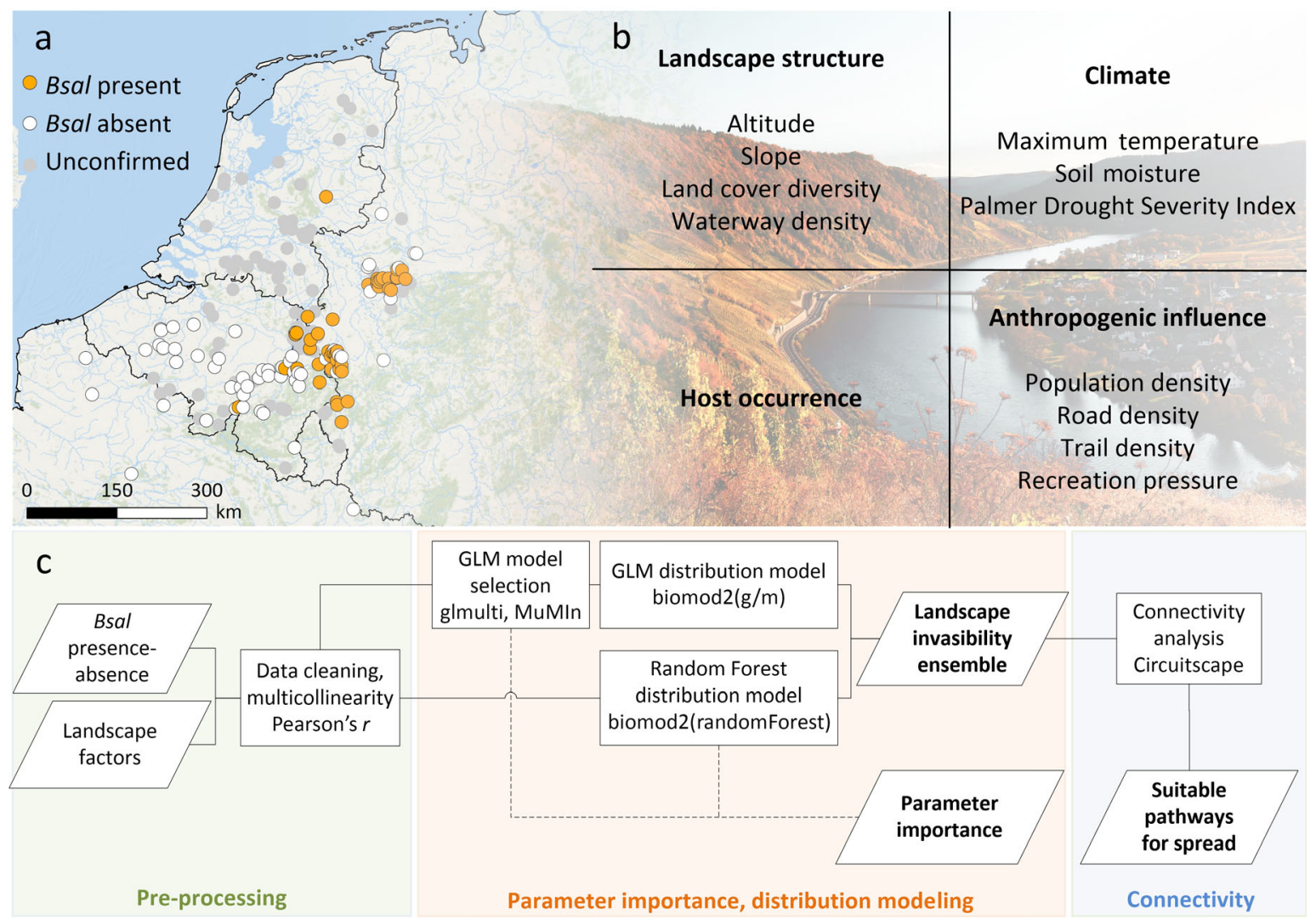

FIG. 1. To characterize landscape epidemiology of Batrachochytrium salamandrivorans (Bsal) in northwestern Europe, we combine (a) survey data with (b) landscape factors to characterize the environment occupied by this pathogen at the regional scale. We then estimate landscape suitability (invasibility) to Bsal and identify potential pathways for further spread. (c) Overview of our methodological pipeline. Moselle River valley photo copyright Bas Meelker/Alamy Stock Photo.

The data set was then revised following diagnostic standards set by Thomas et al. (2018) to reduce the risk of false positives, including histological verification and/ or cross-confirmation of positive samples to minimize qPCR detection error. Confirmation of infection is missing from potential outbreak sites near Duffel (Belgium) and Berg en Dal (the Netherlands), which we therefore removed, along with records of $\mathrm{Bsal}$ in palmate newts, for which Bsal infection has not been confidently diagnosed (Martel et al. 2014). Records lacking accurate coordinates were furthermore removed from the data set, after which sites falling within $1 \mathrm{~km}$ of each other were merged under a single record. We finally retained $47 \mathrm{Bsal}$ presence sites, inhabited by fire salamanders, alpine newts (Ichthyosaura alpestris), smooth newts (Lissotriton vulgaris), great crested newts (Triturus cristatus), or multiple species (Appendix S1: Table S1).

Establishing Bsal absence in a given area is highly challenging because its prevalence may remain exceptionally low, especially in newt populations (Spitzen-van der Sluijs et al. 2016, 2020, Dalbeck et al. 2018). For this reason, fire salamanders were used as a sentinel species to determine disease absence, as this species is highly susceptible to Bsal, and consistently show high pathogen prevalence during epizootic outbreaks (Spitzen-van der Sluijs et al. 2016, 2020, Dalbeck et al. 2018). Firstly, we therefore removed all sites at which Bsal absence was indicated based on newts only, or at which only anurans were sampled. Second, Bsal causes mass mortality in fire salamanders, with an estimated $90 \%$ population decline within six months (Stegen et al. 2017). The nondetection of mortality in these conspicuous salamanders during population monitoring efforts was therefore used as an additional criterion in determining Bsal absence. Third, numerous reported absence localities throughout our study area are based on a limited subset of sampled fire salamanders. We therefore took a conservative approach by only including absence localities when the pathogen was not encountered in a sample of at least 15 individuals. On the basis of these combined criteria, we excluded 155 Bsal absence localities reported throughout our study area (Appendix S1: Table S1). The final data set included 57 absences. We consider these as representative absence sites at which $\mathrm{Bsal}$ has not caused disease outbreaks and mortality within the study period (but see Discussion). 
TABLE 1. Landscape parameters used as predictors of Batrachochytrium salamandrivorans (Bsal) occurrence, including units, range, and source.

\begin{tabular}{|c|c|c|}
\hline Environmental parameter & Range, unit & Source \\
\hline \multicolumn{3}{|l|}{ Landscape structure } \\
\hline Altitude & $0-1,469 \mathrm{~m}$ & http://srtm.csi.cgiar.org/srtmdata/ \\
\hline Slope & $0.08-6.62^{\circ}$ & Derived from Altitude \\
\hline Land cover diversity (Shannon Index, $H$ ) & $0.90-2.00$ & $\begin{array}{l}\text { Derived from https://land.copernicus.eu/pan- } \\
\text { european/corine-land-cover/clc2018 data }\end{array}$ \\
\hline Waterway density & $0-353$ features/cell & Derived from https://www.geofabrik.de/data \\
\hline \multicolumn{3}{|l|}{ Anthropogenic influence } \\
\hline Population density, mean & $0-23$ people/cell & https://www.worldpop.org/ \\
\hline Major road density & $0-465$ features/cell & Derived from https://www.geofabrik.de/data \\
\hline Minor road density & $0-838$ features/cell & Derived from https://www.geofabrik.de/data \\
\hline Trail density & $31-2168$ features/cell & Derived from https://www.geofabrik.de/data \\
\hline Predicted recreational visits & $0-147,314$ visits & https://doi.org/10.1016/j.jnc.2016.03.001 \\
\hline \multicolumn{3}{|l|}{ Climate factors } \\
\hline Maximum temperature, mean & $11.69-15.57^{\circ} \mathrm{C}$ & https://doi.org/10.1038/sdata.2017.191 \\
\hline Maximum temperature, $\mathrm{SD}$ & $6.27-7.01^{\circ} \mathrm{C}$ & Derived from main parameter \\
\hline Soil moisture, mean & $37.91-58.80$ bar* & https://doi.org/10.1038/sdata.2017.191 \\
\hline Soil moisture, SD & $16.98-27.25$ bar & Derived from main parameter \\
\hline Palmer Drought Severity Index (PDSI), mean & $-1.68-0.35$ & https://doi.org/10.1038/sdata.2017.191 \\
\hline Palmer Drought Severity Index (PDSI), SD & $1.88-2.31$ & Derived from main parameter \\
\hline \multicolumn{3}{|l|}{ Host occurrence } \\
\hline Host species richness & $1-4$ species & $\begin{array}{l}\text { Derived from species-specific data from www.gbif.org; } \\
\text { www.feldherpetologie.de/atlas; www.waarneminge } \\
\text { n.be; www.observations.be; www.amphibiens-champa } \\
\text { gne-ardenne.com }\end{array}$ \\
\hline
\end{tabular}

Note: Appendix S1: Table S2 presents a metadata overview. *1 bar $\equiv 100,000 \mathrm{~Pa}$ (pascal).

\section{Landscape parameters}

To assemble, generate, and crop environmental parameters we used ArcGIS 10.1 (specifically SDMToolbox 1.1c; Brown 2014) and the packages ncdf4, raster, and vegan in R v. 3.5.3 (R Core Team 2019). We initially assembled a data set of 20 parameters covering patterns in landscape structure, anthropogenic influence, climate factors and host occurrence (see Appendix S1: Table S2 for a metadata overview). Collinearity between these was assessed in $\mathrm{R}$ by first $\log _{10}$-transforming parameters with particularly large values, followed by visual inspection of pairwise scatterplots and calculation of Pearson correlation coefficients $(r)$. Four parameters were omitted due to high collinearity ( $r>0.75$ or $r<-0.75$, see Appendix S1: Table S3), resulting in a final data set of 16 predictors summarized in Table 1 and in the following paragraphs.

Climate data were obtained from the TerraClimate database (Abatzoglou et al. 2018), which is updated yearly and therefore gives access to data of which temporal coverage matches with Bsal emergence in our study area (see also Feldmeier et al. 2019). Parameters retained after collinearity was assessed were maximum temperature, soil moisture, and Palmer Drought Severity Index (PDSI). To express information on climate extremes and variability additional to that on mean monthly values, we generated standard deviation maps for each parameter. This approach limits collinearity compared to use of for instance quartiles or absolute extremes, as variability measures are less correlated with means (Zimmermann et al. 2009).

Variation in landscape structure and diversity was represented by four parameters. We derived altitude and slope parameters from a SRTM4.0 Digital Elevation Model, using raster::terrain in $\mathrm{R}$ to determine the latter. Landscape diversity was added through a parameter describing the Shannon diversity index, which we produced by applying the vegan::diversity function in $\mathrm{R}$ to a moving window with a $5 \mathrm{~km}$ radius onto the CORINE Land Cover (CLC) 2018 v.20 data set. The CLC is the primary spatial data source on land for the European Economic Area, which is widely used for indicator development, environmental modeling and land use change analyses (Büttner and Kosztra 2017). Finally, as several Bsal outbreak areas are located close to major waterways including the Meuse, Moselle and the Ruhr, we added a water way density parameter generated with OpenStreetMap data obtained from Geofabrik, using the line density tool in ArcGIS10.1 while accounting for distance decay effect (data available online). ${ }^{9}$

Host occurrence was included in the form of a richness map consisting of distribution records for $S$. salamandra, I. alpestris, L. vulgaris, and T. cristatus.

${ }^{9}$ https://www.geofabrik.de/ 
Because amphibian distribution data at the European level are only available as IUCN expert-drawn maps or $50 \times 50 \mathrm{~km}^{2}$ atlas data, we amalgamated salamander distribution maps from a variety of higher resolution sources (see Appendix S1 for a detailed description).

As globalization increasingly drives pathogen spread and colonization (O'Hanlon et al. 2018, Byrne et al. 2019), our last group of parameters included in the final data set describes patterns in human population density, road density, and recreation pressure. Population density was included through results from a 2018 census obtained through WorldPop (data available online). ${ }^{10}$ Major road, minor road, and trail density were generated as described for the waterway parameter, again based on OpenStreetMap data. Trail density includes footpaths, bridleways, and byways in natural areas and thereby serves as a proxy of outdoor recreation accessibility (Schägner et al. 2016). Furthermore, we included a parameter displaying predicted number of recreational visits per hectare, recently generated by Schägner et al. (2016).

\section{Parameter importance and model building}

We used two approaches to evaluate landscape parameter importance and to fit invasive species distribution models (iSDMs); model selection using Generalized Linear Modeling (GLM), and machine learning, by means of Random Forest analysis. Both these methods perform well under small sample sizes when care is taken to avoid overfitting (Guillera-Arroita et al. 2014, Mi et al. 2017). As GLM presents a statistical approach and Random Forest uses machine learning, we were interested in whether and how relative covariate importance would differ between these approaches provided the data limitations inherent to our study system.

First, we evaluated GLM parameter importance within a selected subset of "best-scoring" models through multimodel inference, based on Akaike's Information Criterion corrected for small data sets $\left(\mathrm{AIC}_{\mathrm{c}}\right)$. The glmulti::glmulti function in $\mathrm{R}$ (Calcagno and de Mazancourt 2010) was used to identify the lowest scoring models among all possible combinations of parameters. Logit link functions were consistently used to accommodate our binomial presence-absence data. No random effects were included. To account for model selection uncertainty, we selected all models that showed an $\mathrm{AIC}_{\mathrm{c}}$ score $\leq 2$ from the most parsimonious model (Grueber et al. 2011). To evaluate and account for potential lack of independence between closely located sites (also see section on iSDM cross-validation), we assessed the residuals of all selected models by means of a Moran's $I$ test using the spdep::moran.test function, but found no significant effects and thus applied no further corrections. The selected models were then averaged using the MuMIn::model.avg function in $\mathrm{R}$ to obtain

\footnotetext{
${ }^{10} \mathrm{https}$ ://www.worldpop.org/
}

final GLM estimates and associated sum of weights of included parameters (Burnham and Anderson 2002). Given the lack of data yet available on Bsal ecology (see Discussion), we refrained from forming and testing explicit ecological hypotheses. As such, we did not base the relative importance of parameters on estimates of $P$ values in relation to null hypotheses, but used the modelaveraged weights as a central measure that is less vulnerable to overfitting and spurious effects in exploring environmental drivers (Johnson and Omland 2004, Grueber et al. 2011).

Second, we evaluated parameter importance through Random Forest (Breiman 2001) based on the Mean Decrease in Gini index, which indicates how often a parameter is chosen to split nodes in a classification tree. To this aim, we grew a forest of 500 classification trees in $\mathrm{R}$ using randomForest::randomForest by drawing a different four-parameter bootstrap sample (a root node) for each tree from our data set. Samples were drawn by randomly selecting $n$ cases with replacement, where $n$ is the total number of presence-absence data points. This data subdivision approach accounts for potential lack of independence among our occurrence sites. About onethird of the samples drawn for every tree were set aside to obtain an estimate of classification error. At each node, a randomly chosen subset of parameters was used to find the best split, which minimizes overfitting. Each tree was grown to the largest extent possible, after which a classification was obtained by putting the samples that were set aside down the tree. Mean decrease in Gini was then determined as the average of a parameter's total decrease in node impurity, weighted by the proportion of samples reaching that node in each individual tree. Higher mean decrease in Gini indicates higher variable importance.

The subset of parameters obtained through the averaged GLM models, and the full parameter data set used for Random Forest, were subsequently combined with Bsal presence-absence data in biomod2 (Thuiller et al. 2016) to fit GLM and Random Forest iSDMs, respectively. We matched model settings to those used in previous model selection steps using biomod2:: BIOMOD_ModelingOptions. This step does, however, not allow predefining GLM parameter coefficients. When building iSDMs, one is frequently faced with issues related to data availability, spatial autocorrelation, environmental non-equilibrium, use of absence data, and model extrapolation (e.g., Dullinger et al. 2009, Václavík and Meentemeyer 2009, 2012, Elith et al. 2010, Jiménez-Valverde et al. 2011, Guillera-Arroita et al. 2015, Uden et al. 2015, Feldmeier et al. 2019). Indeed, while we did not detect a significant lack of independence in model residuals by means of Moran's, spatial autocorrelation between occurrence records may still exist and influence iSDM predictions. To account for these challenges, we calibrated and evaluated our models using buffered (spatial) leave-one-out cross-validation (Le Rest et al. 2014, Roberts et al. 2017). Please refer to 
the Discussion for an overview of our rationale to incorporate absence data, but not native Bsal occurrences. Cross-validation folds were created by iteratively setting a single randomly selected presence-absence combination aside for testing, until no further unique combinations could be made. The number of folds thereby equals the lowest number of available presence or absence records. Training records that fell within the range of spatial autocorrelation ( 0.6 decimal degrees), determined using ecospat::ecospat.mantel.correlogram in $\mathrm{R}$, were then removed from the testing records. Because biomod2 cannot handle cross-validation folds of unequal length, we performed a separate run for each fold. The final invasibility ensemble was generated by weighting each submodel proportionally to its True Skill Statistic (TSS) score (Thuiller et al. 2016). TSS is calculated as model sensitivity + specificity -1 , and thereby ranges between -1 to 1 with 0 indicating that the model is no different than random (Allouche et al. 2006). Only models that scored a TSS of $>0.7$ were considered. Given that our focus was on obtaining an estimate of landscape invasibility we did not perform any post-processing of our invasibility estimates, such as incorporating dispersal restrictions.

\section{Connectivity analyses}

The invasibility ensemble was finally used as conductance surface in Circuitscape (McRae et al. 2013) to identify potential pathways suitable for further Bsal spread. Circuitscape uses electronic circuit theory to predict patterns of movement, gene flow, or genetic differentiation among populations under the assumption of random landscape exploration. This approach accommodates uncertainty on how Bsal spreads (e.g., Spitzenvan der Sluijs et al. 2018), which is more suitable in our case compared to for instance least-cost path analysis.

Circuitscape v. 4.0.5 was implemented through a dedicated ArcGIS 10.1 toolbox (available online). ${ }^{11}$ As the areas north of most Bsal outbreak sites are highly invasible (see Results) we focused on potential for southward spread. To this aim, we first calculated pairwise connectivity between the 47 currently known Bsal outbreak sites, using the invasibility ensemble obtained through distribution modeling as conductance surface. The resulting current maps revealed existence of two highly connected outbreak areas, consisting of the North Eifel and the Ruhr-District with adjacent Münsterland Lowland Bay (Appendix S1: Fig. S1). As recent surveys revealed that $B s a l$ outbreaks in these areas are ongoing (e.g., Wagner et al. 2019b), we then set the North Eifel and the Ruhr-District as focal areas, from which suitability for further spread was determined by calculating pairwise connectivity to seven moderately to highly invasible regions in France and Germany. From west to east, these comprise the Paris and Lille metropolitan areas,

\footnotetext{
${ }^{11} \mathrm{http}: / /$ www.circuitscape.org
}

hills and mountain ranges of the former ChampagneArdennes (now part of Grand Est), the Hunsrück, the Vosges, the Palatinate Forest and the northern Black Forest (Fig. 3a). Finally, we also assessed pairwise connectivity among all areas to determine if suitable pathways for spread exist between these.

\section{Results}

\section{Parameter importance}

The environmental factors showing the highest contribution to the distribution of Bsal were broadly similar between model-averaged GLM estimates and Random Forest analysis, albeit with differences in their relative importance (Fig. 2). A detailed overview of GLM model selection results and model-averaged regression coefficients can be found in Table S4 in Appendix S1. Both GLM and Random Forest analysis attributed a high importance to climatic factors describing variability in water availability (soil moisture SD and PDSI SD) as well as mean maximum temperature and mean PDSI, while mean soil moisture was attributed a relatively lower weight. All of these parameters were indicated to have a negative effect on Bsal presence. Land cover diversity was also an important factor in both analyses, and equally showed a negative correlation. Trail density and slope were highly important based on GLM estimates and were included in all selected models, showing a positive effect on Bsal presence in the case of trail density and negative effect for slope. Yet, both of these parameters were somewhat less important in Random Forest estimates in comparison to climatic factors. With the exception of altitude, the eight parameters discussed above explained most of Bsal presence-absence in both GLM and Random Forest analysis. The remaining explanatory parameters all received the lowest support between the two utilized methods.

\section{Distribution models}

Buffered leave-one-out cross-validation resulted in TSS model evaluation scores of $0,0.5$, or 1.0 , indicating failure to identify both test sites as actual positives and negatives, presence of a single correctly identified test site, or correct identification of both test sites, respectively. Average model scores for GLM (TSS $0.77 \pm 0.40$ ) and Random Forest (TSS $0.79 \pm 0.40$ ) indicated good overall discrimination ability.

GLM predictions estimated high invasibility (relative likelihood of Bsal presence) around outbreak sites in the Ardennes-Eifel and wider Ruhr region, and across the German and Dutch lowlands influenced by the North Sea (Fig. 3). Urban centers throughout our study area receive moderate to high scores, as do most hilly or mountainous regions in German Saarland, Hesse, and particularly in Rhineland-Palatinate and BadenWürttemberg. Invasibility decreases toward the 


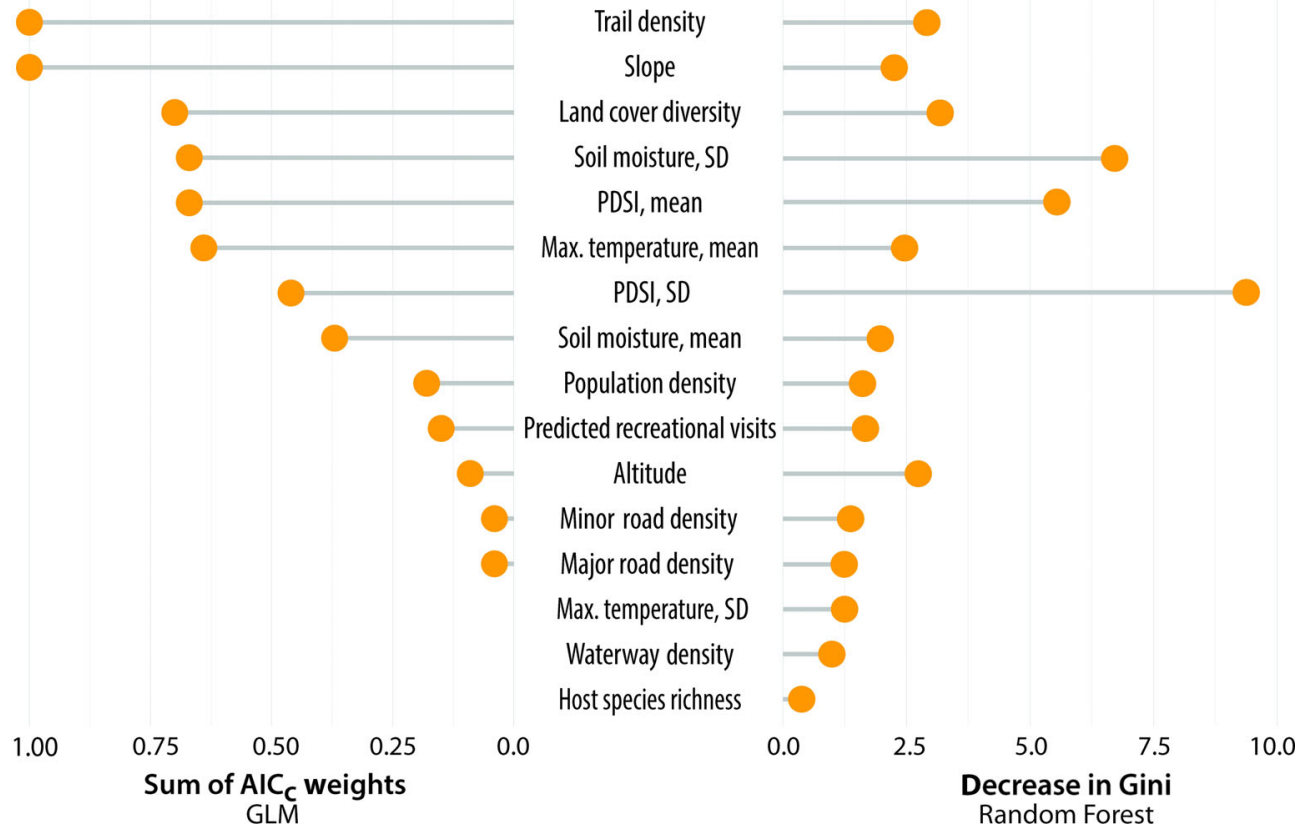

FIG. 2. Relative importance of landscape parameters in explaining the distribution of Batrachochytrium salamandrivorans (Bsal) in northwestern Europe. Parameter importance was obtained using two different approaches: GLM model selection and Random Forest machine learning, and is expressed through the sum of $\mathrm{AIC}_{\mathrm{c}}$ weights across selected GLM models and mean decrease in Gini, respectively. The latter indicates how often the parameter is chosen to split nodes in a Random Forest classification tree. Table S4 in Appendix S1 presents an overview of GLM model selection results and associated regression coefficients.

southwest into France, but remains locally high in the Paris and Lille metropolitan areas and hills and mountains across the Grand-Est administrative region. Random Forest predictions largely followed this pattern, showing high invasibility along the German Hunsrück, Palatine Forest, Black Forest and adjacent hill ranges, and the Vosges. The final ensemble emphasized that low invasibility predominates toward the southwest, while urban centers, the north, and hill and mountain ranges in our study area show moderate to high relative likelihood for Bsal presence.

\section{Connectivity}

Pairwise connectivity calculations based on Bsal presence sites revealed the existence of two outbreak clusters, centered on the North Eifel (Eifel National Park) and the Ruhr-District, both located in North RhineWestphalia, Germany (Appendix S1: Fig. S1). Pairwise connectivity calculated between these clusters and the seven moderate to highly invasible focal areas in France and Germany located further southward showed high current flows through the Ardennes toward France, and through Rhineland-Palatinate toward the Hunsrück (Fig. 4a). Moderate current flows furthermore connected the Ruhr-District to the Palatinate Forest, and both outbreak clusters with the Lille metropolitan area. When calculating pairwise connectivity between all areas additional moderate current flows were identified between most neighboring areas (Fig. 4b). Small, moderately invasible areas located between focal areas support these connections.

\section{DisCUSSION}

We here show that the observed distribution of Batrachochytrium salamandrivorans (Bsal) in northwestern Europe is associated with relatively cool, stable climates. Outbreaks are generally located in areas characterized by low landscape heterogeneity and low steepness of slope, and interspersed by a high density of trails. Within our study area, we found that suitable conditions occur in lowlands influenced by the North Sea, but also in hill and mountain ranges in northeastern France and the lower half of Germany. Connectivity analyses finally reveal that these higher altitudes may act as stepping stones for southward expansion.

Not unexpectedly, we found that Bsal presence, like that of Batrachochytrium dendrobatidis $(B d)$, is strongly associated with environmental parameters pertaining to moisture availability (e.g., Lips et al. 2003, Puschendorf et al. 2009, Murray et al. 2011). The recovered higher presence probability in areas characterized by relatively cool, stable climates may in turn relate to the comparatively low thermal optimum $\left( \pm 15^{\circ} \mathrm{C}\right)$ of the Bsal type strain (Martel et al. 2013, Beukema et al. 2021). In our 


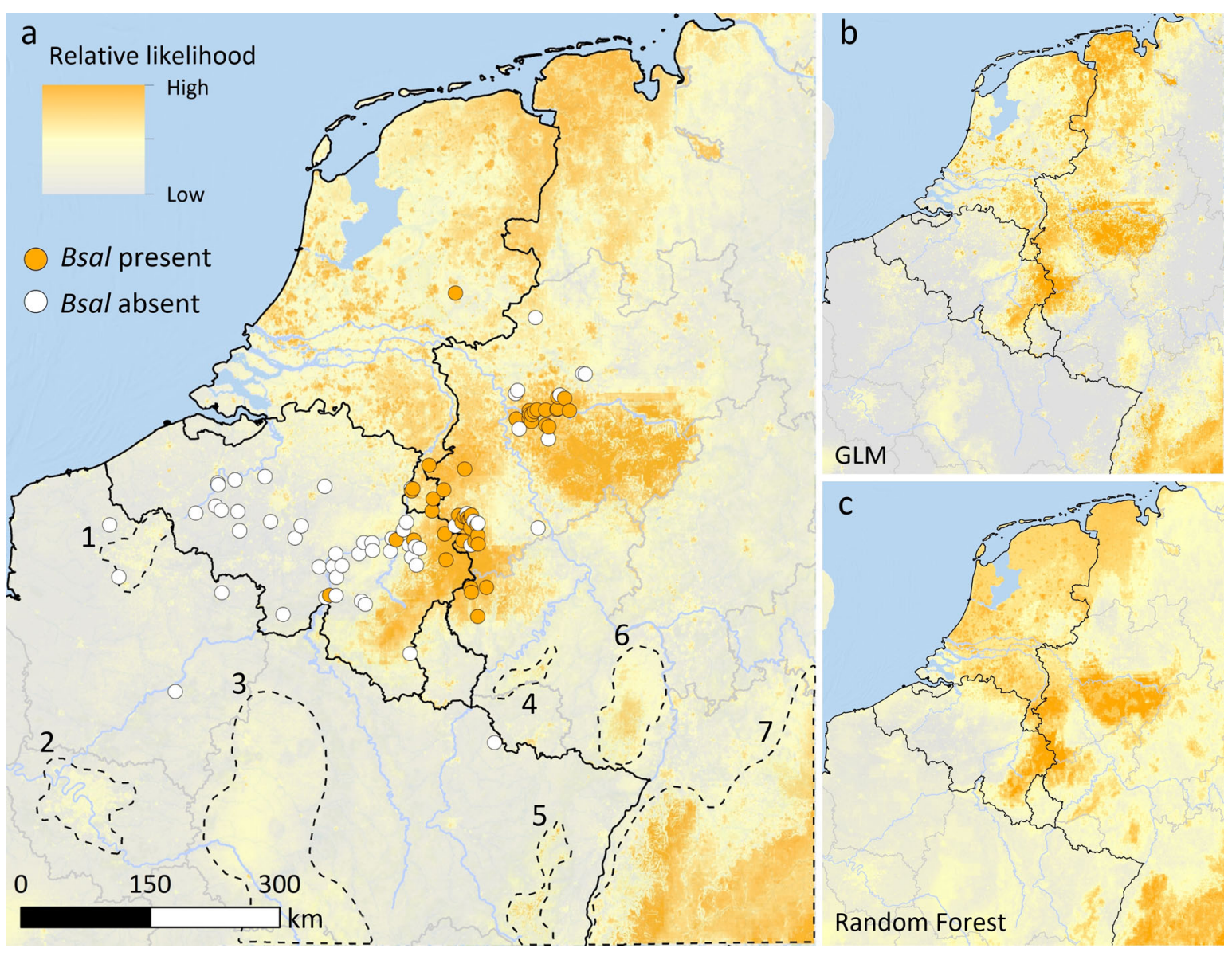

FIG. 3. Landscape invasibility (relative likelihood) to Batrachochytrium salamandrivorans (Bsal) in northwestern Europe. Panel a displays an ensemble of 47 generalized linear models and Random Forest distribution models, of which averages are displayed in panels b and c, respectively. Buffered leave-one-out cross validation was used to build each model, which were trained and evaluated using both presence and absence data. Circles denote the Lille (1) and Paris (2) metropolitan areas, hills and mountain ranges of the former Champagne-Ardennes (3), the Hunsrück (4), Vosges (5), Palatinate Forest (6), and northern Black Forest and adjacent hill ranges (7). State and regional boundaries (gray lines) and main rivers (blue lines) were added for geographical reference.

area, such climate conditions occur in hill and mountain ranges, where Bsal has repeatedly emerged, but also in the oceanic-influenced Dutch and German lowlands from which outbreaks are rarely reported (but see, e.g., Canessa et al. 2020). Bsal occurrence across this lowland region, from which fire salamanders are absent, may, however, be underestimated due to its low prevalence and therefore low detectability in newt populations (Dalbeck et al. 2018, Lötters et al. 2020). Our results hence underline the need for increased monitoring and research efforts to determine how Bsal impacts lowland newts, as well as their role as potential disease reservoirs (Stegen et al. 2017, Schulz et al. 2020).

High invasibility also characterizes most hill and mountain ranges in our study area, especially in Germany (Fig. 3; see also Feldmeier et al. 2016). These predictions are corroborated by recent $\mathrm{Bsal}$ emergence in the southern Eifel Mountains (Sandvoß et al. 2020) and in southern Germany (Schmeller et al. 2020, Thein et al.
2020). Hill and mountain ranges, particularly along the German-French border, may hence act as stepping stones for latitudinal expansion of $B s a l$, which is supported by our connectivity model results (Fig. 4). Our combined findings on importance of landscape and anthropogenic parameters in explaining Bsal presence furthermore suggest that human-mediated dispersion poses an additional risk (Schmidt et al. 2017, Spitzenvan der Sluijs et al. 2018, Lötters et al. 2020). Specifically, moderate to high (outdoor) recreation pressure and easy accessibility of natural areas add to the suitable climatic basis of these stepping stones. Maintaining stringent biosecurity measures and amphibian trade regulations therefore remains critical to constrain $\mathrm{Bsal}$ colonization and spread.

The low invasibility characterizing parts of Belgium and most of France invites the interpretation that extended drought regimes and seasonal extremes might hamper further Bsal advance southward (Fig. 3). These 


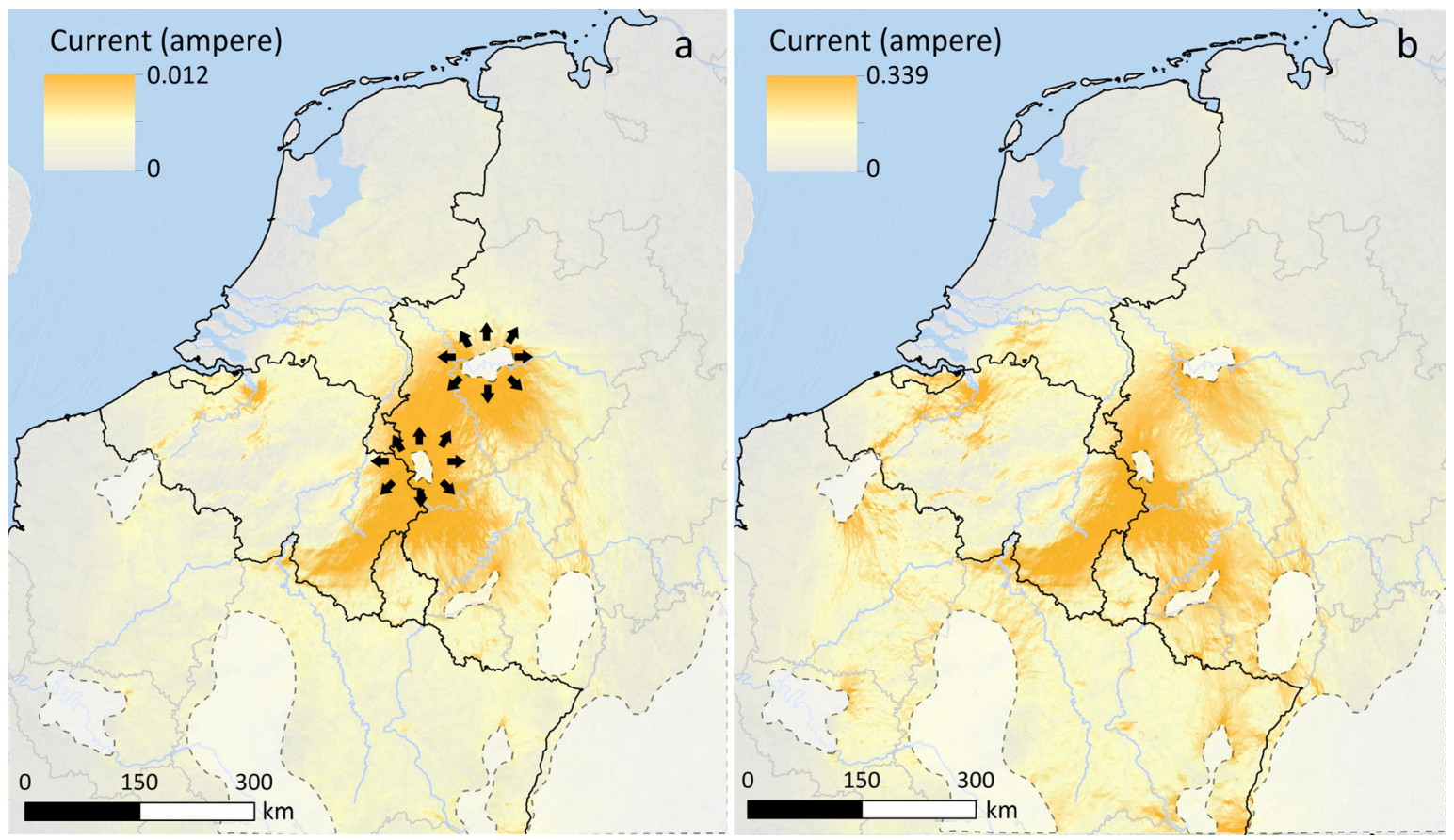

FIG. 4. Connectivity between focal areas in northwestern Europe generated by Circuitscape based on landscape invasibility to Batrachochytrium salamandrivorans ( $\mathrm{Bsal}$ ). (a) Two core outbreak areas, the Nordeifel and the Ruhr-District (indicated by black arrows) were identified, from which connectivity was calculated to seven highly invasible areas further southward (transparent white polygons). Warmer colors indicate higher current density. (b) Pairwise connectivity between all nine areas. State and regional boundaries (gray lines) and main rivers (blue lines) were added for geographical reference.

results should, however, be interpreted with caution due to the scale of our analyses. We assume that the intensely human-modified, fragmented landscape in these regions led to predictions of overall low invasibility to $B s a l$, but the ample potential connectivity currents running across Belgium (Fig. 4) hint at presence of patches vulnerable to Bsal colonization at local level (see also Spitzen-van der Sluijs et al. 2018). Isolated forests or other suitable (micro)habitats may hence still contain susceptible grounds for Bsal epizootics (Beukema et al. 2021). Another artifact of the resolution of our data set may be the association between $\mathrm{Bsal}$ presence and low steepness of slope, given repeated detection of this pathogen in hill and mountain ranges.

We, however, stress that our predictions and estimates of relative parameter importance are affected by Bsal presence being confounded with (host) detection. Specifically, the probabilities of host presence, host detection, and pathogen detection underlie Bsal presence, which violates model assumptions of consistency of parameter relationships with all of the constituent probabilities, or that these parameters only affect the probability of Bsal presence (Lahoz-Monfort et al. 2014). Furthermore, Bsal may not yet fill its potential distribution (i.e., the pathogen is not in equilibrium with its environment), due to which our use of absences may underpredict invasion risk (Elith et al. 2010, Václavík and Meentemeyer
2012). Our results therefore reflect a status quo, which leaves challenges embedded in the observation process, invasion process, and conditional detection process that are in need of improvement to refine future data collection and analyses (Schmidt et al. 2017, Beukema et al. 2018, EFSA Panel on Animal Health and Welfare et al. 2018).

First, our heterogeneous, opportunistically collected Bsal presence-absence data did not allow for quantification of detection rates. To better understand how environmental context shapes $\mathrm{Bsal}$ epizootics, it is critical to account for imperfect detection resulting from observer effects, interspecific differences in host infection prevalence, or diagnostic techniques. This can be done either by accounting for these processes through occupancy modeling and/or incorporating uncertainty in Bayesian frameworks (Adams et al. 2010, Ribeiro et al. 2020). Setting up protocols for consistent host sampling and surveillance efforts is a practical, immediate step to this aim. Occupancy-detection models may also be used to refine spatial risk assessments (Guillera-Arroita et al. 2015).

Second, we here delineate absence data that despite application of a strict range of criteria may include sites where Bsal was present but remained undetected, for instance, during a latency period (Thomas et al. 2018). How Bsal presence builds up and varies during 
subsequent host-pathogen dynamics in invaded salamander populations remains largely unknown. Detailed studies of disease progression in novel outbreak sites are hence warranted to refine true-absence data and, as such, improve the calibration accuracy of statistical models and iSDM predictions.

Third, to improve Bsal iSDMs, presence data from the native Asian range may be used to correct for underprediction (Dullinger et al. 2009, Elith et al. 2010, JiménezValverde et al. 2011). We nevertheless stress that fitting such a "global model" may not account for local environmental conditions that shape the invasive range (e.g., Dullinger et al. 2009). Also, it remains unknown if the Bsal lineage(s) that emerged in Europe are able to attain the full range of conditions occupied across the wide native distribution in East Asia (Martel et al. 2013, Laking et al. 2017). Physiological and genetic data may therefore provide more suitable opportunities to advance spatial Bsal risk assessments. In case of the former, potential variation in for instance thermal performance or growth (e.g., Laking et al. 2017, see also Voyles et al. 2017) may be incorporated in mechanistic models that predict pathogen colonization and spread (Beukema et al. 2021).

In addition, the development of scalable population genomic tools may allow for a retrospective inference of spatial and temporal Bsal spread across outbreak sites that can complement studies rooted in landscape ecology (Byrne et al. 2017, Petkau et al. 2017). In this regard, by integrating environmental and genomic data, future phylogeographic analyses might also aid in disentangling environmental factors that underlie Bsal dispersal (Dellicour et al. 2016). The wide-ranging outbreaks presently seen in European salamander populations (Lötters et al. 2020, Martel et al. 2020) furthermore call for a better understanding of amphibian community dynamics and density-dependent effects in maintaining and spreading disease. Particularly with an expanding host spectrum, the movement ecology of affected species and their life stages might be a key factor in determining disease outcome (Pittman et al. 2014, Daversa et al. 2017, Schulz et al. 2020). Considering the numerous environmental stressors that threaten amphibian populations, detailed ecological studies into Bsal-driven population declines are therefore becoming imperative to inform integrative conservation strategies. A decade after the discovery of Bsal as an imminent threat to salamander diversity, these outstanding questions emphasize the need for continuous and coordinated conservation planning and disease surveillance as knowledge on Bsal increases.

\section{ACKNOWLEDGMENTS}

W. Beukema and J. Erens contributed equally to this work. W. Beukema and J. Erens were supported by the Research Foundation Flanders (FWO) through Ph.D. fellowships 11ZK916N18N and 1173119N. Data collection and processing was made possible by the European Commission (Tender ENV.B.3/SER/2016/0028), Service Public de Wallonie,
Bundesamt fr Naturschutz (FKZ: 3517821000), Deutsche Bundesstiftung Umwelt, Bezirksregierung K-ln, Landesamt fr Natur, Umwelt und Verbraucherschutz, NikolausKochStiftung, DGHT WilhelmPetersFonds and Zoo Landau. We thank Kristijn Swinnen (Natuurpunt Studie) for sharing Belgian newt and salamander occurrence data under UGent Agreement2020095. Jan Philipp Schðgner kindly made spatial data on predicted recreation visits available. We thank Paul Bachhausen, Frederik Bartsch, Lutz Dalbeck, Heidrun Dssel, Julian EnÔ, Stefan Feldmeier, Karin Fischer, Maike Guschal, Kai Kirst, Stefan L-tters, Dagmar Ohlhoff, Sarah Van Praet, Kathleen PreiÔler, Joana SabinoPinto, Martin Schlpmann, Maximilian Schweinsberg, Jeroen Speybroeck, Norman Wagner, Josef Wegge, Michael Veith, Miguel Vences, and Jonas Virgo for logistic assistance, field support, and laboratory work. Comments made by two anonymous reviewers greatly improved an earlier version of this manuscript.

\section{Literature Cited}

Abatzoglou, J. T., S. Z. Dobrowski, S. A. Parks, and K. C. Hegewisch. 2018. TerraClimate, a high-resolution global dataset of monthly climate and climatic water balance from 1958-2015. Scientific Data 5:170191.

Adams, M. J., et al. 2010. Using occupancy models to understand the distribution of an amphibian pathogen, Batrachochytrium dendrobatidis. Ecological Applications 20:289302.

Allouche, O., A. Tsoar, and R. Kadmon. 2006. Assessing the accuracy of species distribution models: prevalence, kappa and the true skill statistic (TSS). Journal of Applied Ecology 43:1223-1232.

Beukema, W., et al. 2018. Environmental context and ecological niche change influence estimation of Batrachochytrium salamandrivorans invasion risk in the Western Palearctic. Diversity and Distributions 24:1788-1801.

Beukema, W., et al. 2021. Microclimate limits thermal behaviour favourable to disease control in a nocturnal amphibian. Ecology Letters 24:27-37.

Blaustein, A. R., B. A. Han, R. A. Relyea, P. T. Johnson, J. C. Buck, S. S. Gervasi, and L. B. Kats. 2011. The complexity of amphibian population declines: understanding the role of cofactors in driving amphibian losses. Annals of the New York Academy of Sciences 1223:108-119.

Blooi, M., F. Pasmans, J. E. Longcore, A. Spitzen-van der Sluijs, F. Vercammen, and A. Martel. 2013. Duplex real-time PCR for rapid simultaneous detection of Batrachochytrium dendrobatidis and Batrachochytrium salamandrivorans in amphibian samples. Journal of Clinical Microbiology 51:4173-4177.

Bozzuto, C., B. R. Schmidt, and S. Canessa. 2020. Active responses to outbreaks of infectious wildlife diseases: objectives, strategies and constraints determine feasibility and success. Proceedings of the Royal Society B 287:20202475.

Breiman, L. 2001. Random forests. Machine Learning 45:5-32.

Brown, J. L. 2014. SDM toolbox: a python-based GIS toolkit for landscape genetic, biogeographic and species distribution model analyses. Methods in Ecology and Evolution 5:694 700.

Burnham, K. P., and D. R. Anderson. 2002. Model selection and multimodel inference. Springer, New York, New York, USA.

Büttner, G., and B. Kosztra. 2017. CLC2018 technical guidelines. European Environment Agency, Vienna, Austria.

Byrne, A. Q., et al. 2019. Cryptic diversity of a widespread global pathogen reveals expanded threats to amphibian 
conservation. Proceedings of the National Academy of Sciences USA 116:20382-20387.

Byrne, A. Q., A. P. Rothstein, T. J. Poorten, J. Erens, M. L. Settles, and E. B. Rosenblum. 2017. Unlocking the story in the swab: A new genotyping assay for the amphibian chytrid fungus Batrachochytrium dendrobatidis. Molecular Ecology Resources 17:1283-1292.

Calcagno, V., and C. de Mazancourt. 2010. glmulti: An R package for easy automated model selection with (generalized) linear models. Journal of Statistical Software 34:1-29.

Canessa, S., et al. 2020. Conservation decisions under pressure: Lessons from an exercise in rapid response to wildlife disease. Conservation Science and Practice 2:e141.

Carter, E. D., et al. 2020. Conservation risk of Batrachochytrium salamandrivorans to endemic lungless salamanders. Conservation Letters 13:e12675.

Dalbeck, L., et al. 2018. Die Salamanderpest und ihr Erreger Batrachochytrium salamandrivorans (Bsal): aktueller Stand in Deutschland. Zeitschrift für Feldherpetologie 25:1-22.

Daversa, D. R., A. Fenton, A. I. Dell, T. W. J. Garner, and A. Manica. 2017. Infections on the move: how transient phases of host movement influence disease spread. Proceedings of the Royal Society B 284:20171807.

Dellicour, S., R. Rose, and O. G. Pybus. 2016. Explaining the geographic spread of emerging epidemics: a framework for comparing viral phylogenies and environmental landscape data. BMC Bioinformatics 17:82.

Dullinger, S., I. Kleinbauer, J. Peterseil, M. Smolik, and F. Essl. 2009. Niche based distribution modelling of an invasive alien plant: effects of population status, propagule pressure and invasion history. Biological Invasions 11:2401-2414.

EFSA Panel on Animal Health and Welfare, et al. 2018. Risk of survival, establishment and spread of Batrachochytrium salamandrivorans (Bsal) in the EU. EFSA Journal 16:78.

Elith, J., M. Kearney, and S. Phillips. 2010. The art of modelling range-shifting species. Methods in Ecology and Evolution $1: 330-342$.

Feldmeier, S., S. Lötters, and M. Veith. 2019. The importance of biological plausibility for data poor models in the face of an immediate threat by an emerging infectious disease: a reply to Katz and Zellmer (2018). Biological Invasions 21:27892793.

Feldmeier, S., L. Schefczyk, N. Wagner, G. Heinemann, M. Veith, and S. Lötters. 2016. Exploring the distribution of the spreading lethal salamander chytrid fungus in its invasive range in Europe - a macroecological approach. PLoS ONE 11:e0165682.

Grueber, C. E., S. Nakagawa, R. J. Laws, and I. G. Jamieson. 2011. Multimodel inference in ecology and evolution: challenges and solutions. Journal for Evolutionary Biology 24:699-711.

Guillera-Arroita, G., et al. 2014. ,Maxent is not a presence-absence method: a comment on Thibaud et al. Methods in Ecology and Evolution 5:1192-1197.

Guillera-Arroita, G., J. J. Lahoz-Monfort, J. Elith, A. Gordon, H. Kujala, P. E. Lentini, M. A. McCarthy, R. Tingley, and B. A. Wintle. 2015. Is my species distribution model fit for purpose? Matching data and models to applications. Global Ecology and Biogeography 24:276-292.

Jiménez-Valverde, A., A. T. Peterson, J. Soberón, J. M. Overton, P. Aragón, and J. M. Lobo. 2011. Use of niche models in invasive species risk assessments. Biological Invasions 13:2785-2797.

Johnson, J. B., and K. S. Omland. 2004. Model selection in ecology and evolution. Trends in Ecology \& Evolution 19:101-108.
Katz, T. S., and A. J. Zellmer. 2018. Comparison of model selection technique performance in predicting the spread of newly invasive species: a case study with Batrachochytrium salamandrivorans. Biological Invasions 20:2107-2119.

Lahoz-Monfort, J. J., G. Guillera-Arroita, and B. A. Wintle. 2014. Imperfect detection impacts the performance of species distribution models. Global Ecology and Biogeography 23:504-515.

Laking, A., H. N. Ngo, F. Pasmans, A. Martel, and T. T. Nguyen. 2017. Batrachochytrium salamandrivorans is the predominant chytrid fungus in Vietnamese salamanders. Scientific Reports 7:44443.

Le Rest, K., D. Pinaud, P. Monestiez, J. Chadoeuf, and V. Bretagnolle. 2014. Spatial leave-one-out cross-validation for variable selection in the presence of spatial autocorrelation. Global Ecology and Biogeography 23:811-820.

Lips, K. R., J. D. Reeve, and L. R. Witters. 2003. Ecological traits predicting amphibian population declines in Central America. Conservation Biology 17:1078-1088.

Lötters, S., et al. 2020. The amphibian pathogen Batrachochytrium salamandrivorans in the hotspot of its European invasive range: past-present—future. Salamandra 56:173-188.

Lötters, S., N. Wagner, A. Kerres, M. Vences, S. Steinfartz, J. Sabino-Pinto, L. Seufer, K. Preißler, V. Schulz, and M. Veith. 2018. First report of host co-infection of parasitic amphibian chytrid fungi. Salamandra 54:287-290.

Martel, A., et al. 2013. Batrachochytrium salamandrivorans sp. nov. causes lethal chytridiomycosis in amphibians. Proceedings of the National Academy of Sciences USA 110:1532515329.

Martel, A., et al. 2014. Recent introduction of a chytrid fungus endangers Western Palearctic salamanders. Science 346:630 631.

Martel, A., et al. 2020. Integral chain management of wildlife diseases. Conservation Letters 13:e12707.

McRae, B. H., V. B. Shah, and T. K. Mohapatra. 2013. Circuitscape 4 User Guide. The Nature Conservancy. http:// www.circuitscape.org

Mi, C., F. Huettmann, Y. Guo, X. Han, and L. Wen. 2017. Why choose Random Forest to predict rare species distribution with few samples in large undersampled areas? Three Asian crane species models provide supporting evidence. PeerJ 5: e2849.

Murray, K. A., R. W. R. Retallick, R. Puschendorf, L. F. Skerratt, D. Rosauer, H. I. McCallum, L. Berger, R. Speare, and J. VanDerWal. 2011. Assessing spatial patterns of disease risk to biodiversity: implications for the management of the amphibian pathogen, Batrachochytrium dendrobatidis. Journal of Applied Ecology 48:163-173.

O'Hanlon, S. J., et al. 2018. Recent Asian origin of chytrid fungi causing global amphibian declines. Science 360:621-627.

Petkau, A., et al. 2017. SNVPhyl: a single nucleotide variant phylogenomics pipeline for microbial genomic epidemiology. Microbial Genomics 3:e000116.

Pittman, S. E., M. S. Osbourn, and R. D. Semlitsch. 2014. Movement ecology of amphibians: a missing component for understanding population declines. Biological Conservation 169:44-53

Puschendorf, R., A. C. Carnaval, J. VanDerWal, H. ZumbadoUlate, G. Chaves, F. Bolaños, and R. A. Alford. 2009. Distribution models for the amphibian chytrid Batrachochytrium dendrobatidis in Costa Rica: proposing climatic refuges as a conservation tool. Diversity and Distributions 15:401-408.

R Core Team. 2019. R: A language and environment for statistical computing. R Foundation for Statistical Computing, Vienna, Austria. 
Ribeiro, J. W., T. Siqueira, G. V. DiRenzo, C. Lambertini, M. L. Lyra, L. F. Toledo, C. F. B. Haddad, and C. G. Becker. 2020 Assessing amphibian disease risk across tropical streams while accounting for imperfect pathogen detection. Oecologia 193:237-248.

Roberts, D. R., et al. 2017. Cross-validation strategies for data with temporal, spatial, hierarchical, or phylogenetic structure. Ecography 40:913-929.

Sandvoß, M., M. Wagner, S. Lötters, S. Feldmeier, V. Schulz, S. Steinfartz, and M. Veith. 2020. Spread of the pathogen Batrachochytrium salamandrivorans and large-scale absence of larvae suggest unnoticed declines of the European fire salamander in the southern Eifel Mountains. Salamandra $56: 215-226$.

Schägner, J. P., L. Brander, J. Maes, M. L. Paracchinia, and V. Hartje. 2016. Mapping recreational visits and values of European National Parks by combining statistical modelling and unit value transfer. Journal for Nature Conservation 31:7184.

Scheele, B. C., et al. 2019. Amphibian fungal panzootic causes catastrophic and ongoing loss of biodiversity. Science 363:1459-1463.

Schmeller, D. S., R. Utzel, F. Pasmans, and A. Martel. 2020. Batrachochytrium salamandrivorans kills alpine newts (Ichthyosaura alpestris) in southernmost Germany. Salamandra 56:230-232.

Schmidt, B. R., C. Bozzuto, S. Lötters, and S. Steinfartz. 2017. Dynamics of host populations affected by the emerging fungal pathogen Batrachochytrium salamandrivorans. Royal Society Open Science 4:160801.

Schulz, V., et al. 2020. Batrachochytrium salamandrivorans in the Ruhr District, Germany: history, distribution, decline dynamics and disease symptoms of the salamander plague. Salamandra 56:189-214.

Schulz, V., S. Steinfartz, A. Geiger, K. Preißler, J. Sabino-Pinto, M. Krisch, N. Wagner, and M. Schlüpmann. 2018. Ausbreitung der Salamanderpest in Nordrhein-Westfalen. Natur in NRW 4:26-30.

Spitzen-van der Sluijs, A., et al. 2013. Rapid enigmatic decline drives the fire salamander (Salamandra salamandra) to the edge of extinction in the Netherlands. Amphibia-Reptilia $34: 233-239$

Spitzen-van der Sluijs, A., et al. 2016. Expanding distribution of lethal amphibian fungus Batrachochytrium salamandrivorans in Europe. Emerging Infectious Diseases 22:1286-1288.

Spitzen-van der Sluijs, A., T. Stark, T. DeJean, E. Verbrugghe, J. Herder, M. Gilbert, J. Janse, A. Martel, F. Pasmans, and A. Valentini. 2020. Using environmental DNA for detection of Batrachochytrium salamandrivorans in natural water. Environmental DNA 2:565-571.

Spitzen-van der Sluijs, A., G. Stegen, S. Bogaerts, S. Canessa, S. Steinfartz, N. Janssen, W. Bosman, F. Pasmans, and A. Martel. 2018. Post-epizootic salamander persistence in a disease-free refugium suggests poor dispersal ability of Batrachochytrium salamandrivorans. Scientific Reports 8:3800.
Stegen, G., et al. 2017. Drivers of salamander extirpation mediated by Batrachochytrium salamandrivorans. Nature 544:353-358.

Stuart, S. N., J. S. Chanson, N. A. Cox, B. E. Young, A. S. L. Rodrigues, D. L. Fischman, and R. W. Waller. 2004. Status and trends of amphibian declines and extinctions worldwide. Science 306:1783-1786.

Thein, J., U. Reck, C. Dittrich, A. Martel, V. Schulz, and G. Hansbauer. 2020. Preliminary report on the occurrence of Batrachochytrium salamandrivorans in the Steigerwald, Bavaria, Germany. Salamandra 56:227-229.

Thomas, V., et al. 2019. Mitigating Batrachochytrium salamandrivorans in Europe. Amphibia-Reptilia 40:265-290.

Thomas, V., M. Blooi, P. Van Rooij, S. Van Praet, E. Verbrugghe, E. Grasselli, M. Lukac, S. Smith, F. Pasmans, and A. Martel. 2018. Recommendations on diagnostic tools for Batrachochytrium salamandrivorans. Transboundary and Emerging Diseases 65:e478-e488.

Thuiller, W., D. Georges, R. Engler, and F. T. Breiner. 2016. Biomod2 - Ensemble Platform for Species Distribution Modeling. R package version 3.3-7. Retrieved from https:// CRAN.R-project.org/package $=$ biomod 2

Uden, D., C. R. Allen, D. G. Angeler, L. Corral, and K. A. Fricke. 2015. Adaptive invasive species distribution models: a framework for modeling incipient invasions. Biological Invasions 17:2831-2850.

Václavík, T., and R. K. Meentemeyer. 2009. Invasive species distribution modeling (iSDM): Are absence data and dispersal constraints needed to predict actual distributions? Ecological Modelling 220:3248-3258.

Václavík, T., and R. K. Meentemeyer. 2012. Equilibrium or not? Modelling potential distribution of invasive species in different stages of invasion. Diversity and Distributions 18:73-83.

Voyles, J., L. R. Johnson, J. Rohr, R. Kelly, C. Barron, D. Miller, J. Minster, and E. B. Rosenblum. 2017. Diversity in growth patterns among strains of the lethal fungal pathogen Batrachochytrium dendrobatidis across extended thermal optima. Oecologia 184:363-373.

Wagner, N., et al. 2019a. Aktueller Kenntnisstand zur Verbreitung des Erregers der Salamanderpest (Batrachochytrium salamandrivorans) in Rheinland-Pfalz Dendrocopos. 46:35-66.

Wagner, N., et al. 2019b. Aktuelle Erkenntnisse zum Status der Salamanderpest in Deutschland. Natur und Landschaft 94:463-471

Wake, D. B., and V. T. Vredenburg. 2008. Are we in the midst of the sixth mass extinction? A view from the world of amphibians. Proceedings of the National Academy of Sciences USA 105:11466-11473.

Yap, T. A., M. S. Koo, R. F. Ambrose, D. B. Wake, and V. T. Vredenburg. 2015. Averting a North American biodiversity crisis. Science 349:481-482.

Zimmermann, N. E., N. G. Yoccoz, T. C. Jr Edwards, E. S. Meier, W. Thuiller, A. Guisan, D. R. Schmatz, and P. B. Pearman. 2009. Climatic extremes improve predictions of spatial patterns of tree species. Proceedings of the National Academy of Sciences USA 106:19723-19728.

\section{SUPPORTING INFORMATION}

Additional supporting information may be found online at: http://onlinelibrary.wiley.com/doi/10.1002/eap.2342/full

\section{Data Availability}

Distribution data used for model building is provided in Appendix S1: Table S1, and Appendix S1: Table S2 presents a metadata overview. 